\title{
Aging of D-Limonene-Cleaned Assemblies, Final Report
}

\author{
Kansas City Division
}

T. A. Somer

KCP-613-5568

Published August 1995

Final Report

Approved for public release; distribution is unlimited.

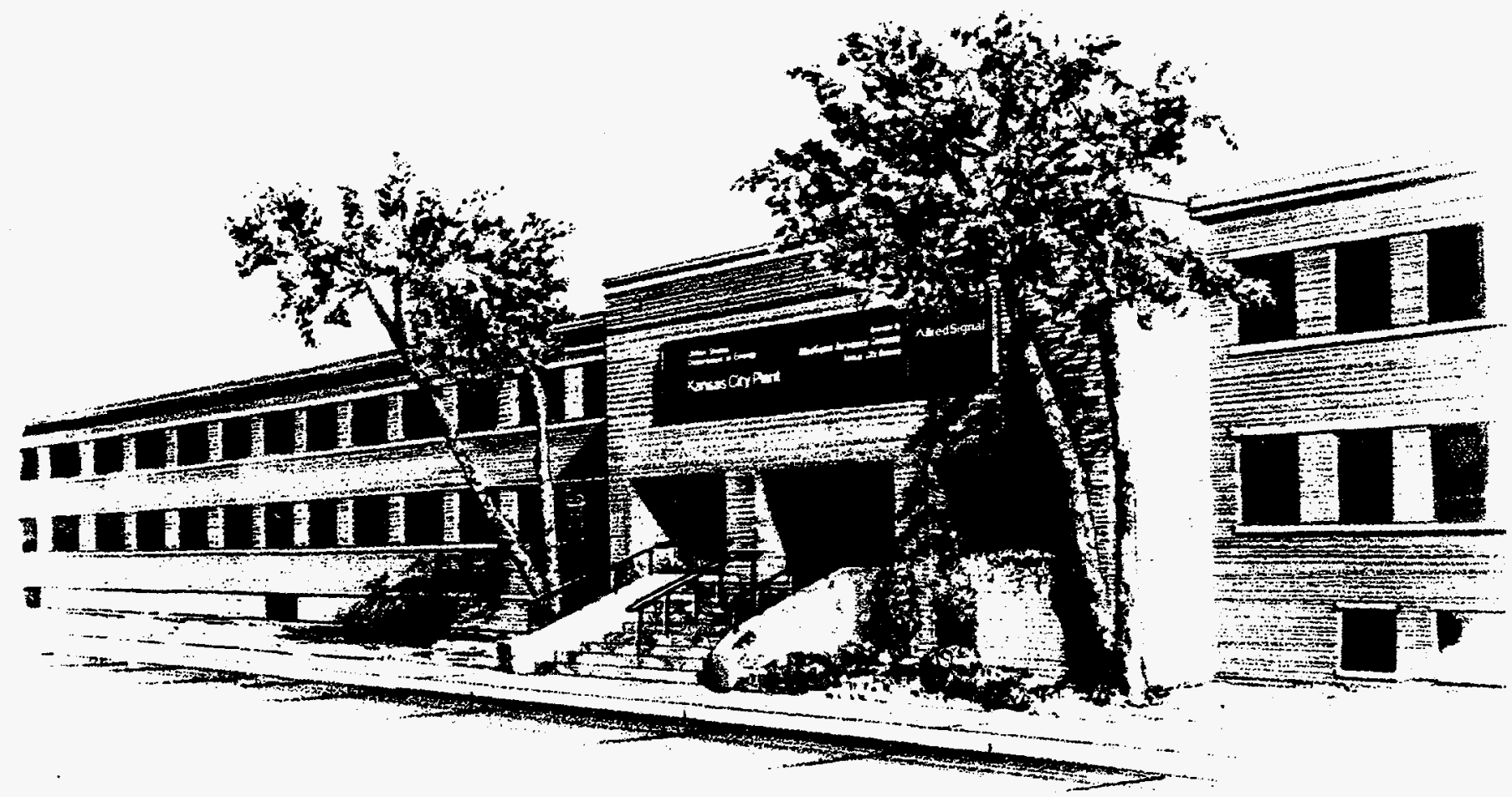




\section{DISCLAIMER}

This report was prepared as an account of work sponsored by an agency of the United States Government. Neither the United States Government nor any agency thereof, nor any of their employees, makes any warranty, express or implied, or assumes any legal liability or responsibility for the accuracy, completeness, or usefulness of any information, apparatus, product, or process disclosed, or represents that its use would not infringe privately owned rights. Reference herein to any specific commercial product, process, or service by trade names, trademark, manufacturer, or otherwise, does not necessarily constitute or imply its endorsement, recommendation, or favoring by the United States Government or any agency thereof. The views and opinions of authors expressed herein do not necessarily state or reflect those of the United States Government or any agency thereof.

Printed in the United States of America.

This report has been reproduced from the best available copy.

Available to DOE and DOE contractors from the Office of Scientific and Technical Information, P. O. Box 62, Oak Ridge, Tennessee 37831; prices available from (615) 576-8401, FTS 626-8401.

Available to the public from the National Technical Information Service, U. S. Department of Commerce, 5285 Port Royal Rd., Springfield, Virginia 22161. 


\section{DISCLAIMER}

Portions of this document may be illegible in electronic image products. Images are produced from the best available original document. 
KCP-613-5568

Distribution Category UC-706

Approved for public release; distribution is unlimited.

\section{AGING OF D-LIMONENE-CLEANED ASSEMBLIES, FINAL REPORT}

T. A. Somer

Published August 1995

Final Report

T. A. Somer, Project Leader 


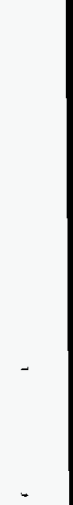




\section{Contents}

$\begin{array}{ll}\text { Section Page } & \text { Pag }\end{array}$

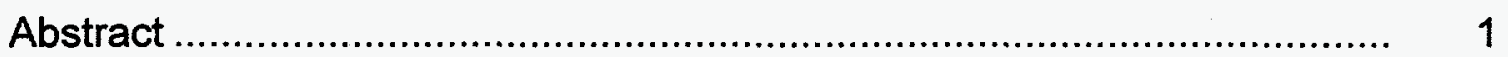

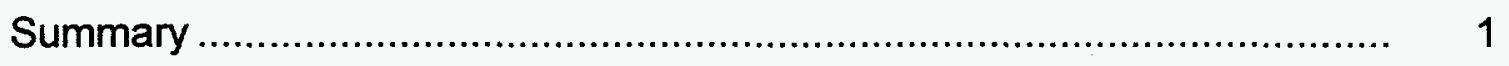

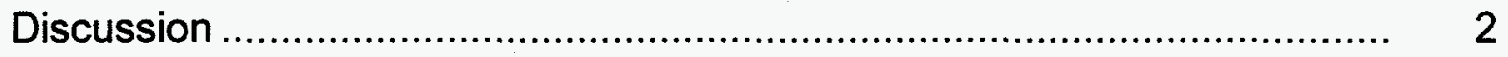

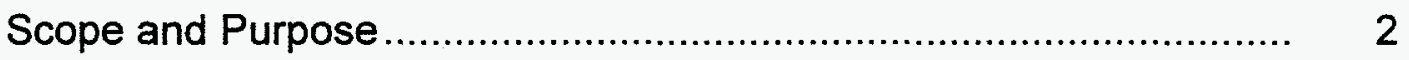

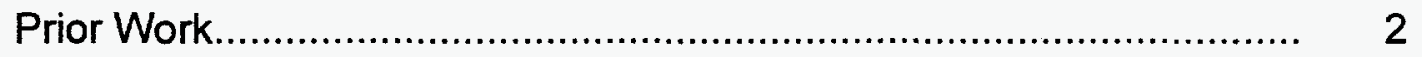

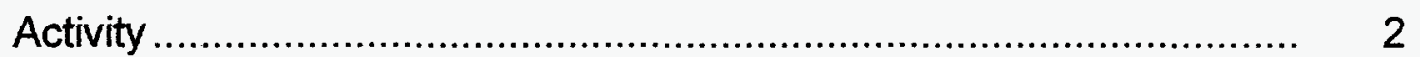

Sample Groups ............................................................. 2

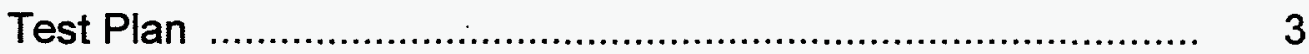

Observations ..................................................................... 3

Accomplishments ................................................................... 5

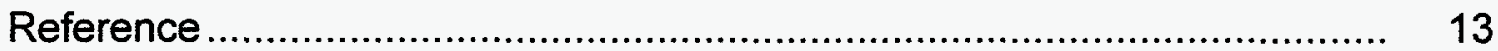




\section{Illustrations}

Figure

Page

1 Control Group Sample at Room Temperature--Circuit Path

Resistance of Two Connectors, Path on Circuit Board and

Wire, Cleaned With TCE/IPA........................................................... 6

2 Circuit Path Resistance of Two Connectors, Circuit Board, and

Wire--8000 Hours at $+160^{\circ} \mathrm{F}$, Saturated D-Limonene Atmosphere,

Cleaned With TCE/IPA

7

3 Circuit Path Resistance of Two Connectors, Circuit Board Path and Wire-- 8000 Hours at $+160^{\circ} \mathrm{F}$, Cleaned With TCE/IPA .

8

4 Circuit Path Resistance of Two Connectors, Circuit Board Path and Wire- -3800 Hours at $+160^{\circ} \mathrm{F}$, Cleaned With D-Limonene/IPA...... 9

5 Control Group Sample at Room Temperature, Leakage Current at 40 Volts, 14 Filtered Lines, TCE/IPA Cleaned

6 Leakage Current for 14 Filtered Lines (Ave) at 40 Volts--8000 Hours at $+160^{\circ} \mathrm{F}$, Saturated D-Limonene Atmosphere, TCE/PA Cleaned .... 11

7 D-Limonene/IPA Cleaned Assemblies--3800 Hours at $+160^{\circ} \mathrm{F} \ldots \ldots \ldots .$. 


\begin{abstract}
The performance of 1600 electronic circuit variables was monitored throughout an 8000 -hour exposure to $+160^{\circ} \mathrm{F}$. The variables involve 36 electronic assemblies, cleaned with various solvents, including $d$-Limonene, as a replacement for trichloroethylene (TCE). The assemblies were divided into four groups, including a TCE-cleaned control group at room temperature. Of the three groups exposed at $+160^{\circ} \mathrm{F}$, one was cleaned in TCE, one was cleaned in $d$-Limonene, and one was kept in a saturated $d$-Limonene atmosphere. No performance degradation was observed with any of the groups, including the worst-case exposure in a saturated d-Limonene atmosphere.
\end{abstract}

\title{
Summary
}

This project studied the aging of selected electronic assemblies and cables cleaned with various solvents, some with d-Limonene and others with trichloroethylene (TCE) and isopropyl alcohol (IPA). The electrical performance of 36 assemblies was monitored for 8000 hours. Data has been collected from samples divided into four groups:

- Control group at $+75^{\circ} \mathrm{F}$,

- $\mathrm{TCE} / \mathrm{IPA}$-cleaned at $+160^{\circ} \mathrm{F}$,

- D-Limonene/lPA-cleaned at $+160^{\circ} \mathrm{F}$, and

- Saturated d-Limonene atmosphere at $+160^{\circ} \mathrm{F}$.

The study included twelve 28-channel high voltage transient suppresser assemblies, ten 20-position rotary switch assemblies, six CF2906 cables, and eight CF2907 cables, with over 2000 measured electrical parameters. All units were tested 13 times during the 8000-hour study.
The most important observation is that the exposure to a saturated d-Limonene atmosphere at $+160^{\circ} \mathrm{F}$ for 8000 hours has not produced any detectable changes in the electrical performance of the measured parameters. Furthermore, there are no performance differences among the four groups and no time/age-correlated performance degradation. 


\section{Discussion}

\section{Scope and Purpose}

Some minute quantity of $d$-Limonene can and will remain in an assembly or can get into components during the $d$-Limonene cleaning process; therefore, there is a concern about d-Limonene's long-term effects on electrical parameters and/or circuit reliability. This study focuses on the aging characteristics of circuits cleaned with d-Limonene and also on assemblies where established cleaning methods were used.

\section{Prior Work}

This work was started to supplement massive efforts in evaluating $d$-Limonene as a replacement solvent for TCE. One important consideration for a replacement solvent is cleaning efficiency, which was amply demonstrated for $\mathrm{d}$-Limonene in an earlier study. ${ }^{1}$ Investigation of the long-term aging effects of $d$-Limonene on electronic assemblies and associated components and materials was imperative to ensure systems compatibility.

\section{Activity}

\section{Sample Groups}

Test samples were selected and prepared. All samples were aged without the application of power. The units were powered up only during periodic electrical testing after being stabilized at $70^{\circ} \mathrm{F}$. All units were tested a minimum of 13 times during the study.

\section{Control Group at $+75^{\circ} \mathrm{F}$}

The control group included two 28-channel high voltage transient suppresser assemblies, two 20-position rotary switch assemblies, one
CF2906, and two CF2907s. Units in this group are characterized by 137 highimpedance measurements ( $R>10^{\circ}$ ohms), 91 low-impedance measurements ( $R<0.06 \mathrm{ohms}$ ), and $68 \mathrm{mid}$-impedance measurements.

\section{TCE/IPA Cleaned Group at $+160^{\circ} \mathrm{F}$}

This group included three 28-channel high voltage transient suppresser assemblies, three 20-position rotary switch assemblies, two CF2906s, and three CF2807s. This group is characterized by 208 highimpedance measurements, 138 lowimpedance measurements, and 102 midimpedance measurements.

\section{D-Limonene/IPA Cleaned Group at $+160^{\circ} \mathrm{F}$}

This group included two 28-channel high voltage transient suppresser assemblies, three 20-position rotary switch assemblies, two CF2906s, and two CF2907s. This group is characterized by 162 high-impedance measurements, 114 low-impedance measurements, and 68 mid-impedance measurements.

\section{D-Limonene-Saturated Atmosphere at $+160^{\circ} \mathrm{F}$}

There were five 28 -channel high voltage transient suppresser assemblies, two 20-position rotary switch assemblies, one CF2906, and one CF2907 in saturated $\mathrm{d}$-Limonene atmosphere at $+160^{\circ} \mathrm{F}$, which is considered a worst-case situation. This group is characterized by 255 highimpedance measurements, 151 lowimpedance measurements, and 170 midimpedance measurements. 
Each group of samples was stored in a separate desiccator and the only time the samples were removed from desiccators was for electrical testing. The saturated d-Limonene atmosphere was maintained by keeping a small open container of $d$-Limonene solvent inside the desiccator with the samples. D-Limonene solvent was added periodically to compensate for losses caused by evaporation.

\section{Test Plan}

At the beginning of the study, before the temperature exposure, all units were tested several times to establish a room temperature baseline. At the time the study was started, there was no information about aging characteristics of electrical parameters in the presence of $d$-Limonene. To avoid the risk of damaging all of the samples early in the study, the evaluation was started with frequent testing and short temperature exposures at $+160^{\circ} \mathrm{F}$.

Initially, the units in the saturated d-Limonene atmosphere were tested every 24 hours; the other groups were tested every 150 hours. After no performance degradation was observed, the time between electrical testing was gradually increased to the present 700 hours. For testing, the samples were removed from the elevated temperature and then allowed to stabilize at room temperature. All DC testing was being performed on the PT3300 multipurpose tester. The PT3300 is part of a network data acquisition system (DAS), which facilitates data collection.

\section{Observations}

More than 24,000 data points from 22 assemblies and 14 high-voltage cables have been collected and stored in the DAS system during the study. Because the DAS system is limited in time-related statistical data manipulation and data consolidation, the data was transferred into the mainframe CMS system. In the CMS system, like variables for each serial number were combined and the mean and \pm 3 standard deviation were calculated at each test date.

No time-related performance degradation has been detected in any of the samples including the worst-case samples in saturated $\mathrm{d}$-Limonene atmosphere at $+160^{\circ} \mathrm{F}$ for 8000 hours.

Over 1600 electrical parameters were tested and monitored throughout the 8000-hour study; however, not all electrical parameters would be equally sensitive to solvent/contamination-induced aging effects. The first class of aging effects are primarily surface effects. Here measurements involving low level leakage currents (insulation resistance $R \geq 10^{9}$ ohms) or very low-level resistance (contact resistance $\mathrm{R} \leq 10^{-2}$ ohms) would most likely show solvent/contamination-induced aging effects. Measurements of electrical parameters when the source impedances range from $1 \mathrm{ohm}$ to $10^{6}$ ohms would mask the aging effects, if present.

A second class of problems is caused by mechanical flaws in hermetic seals or component coatings. These failures will allow the solvent to enter the device. Active devices are likely to fail early in life when the cleaning solvent (any cleaning solvent) penetrates the active areas of the device. Passive components would not develop immediate failures when the cleaning solvents penetrate the coating and, therefore, can show aging effects--depending on impedance levels.

With this in mind, the most extreme and sensitive parameters were selected to summarize the aging study results. 
Figure 1 shows data for two low-resistance circuits in a 28-channel high voltage transient suppresser assembly (part of the control group) at $75^{\circ} \mathrm{F}$. (All figures appear following the text.) Figure 2 shows the data for the identical two circuits but in a different 28-channel high voltage transient suppresser assembly in the saturated d-Limonene atmosphere at $+160^{\circ} \mathrm{F}$ for 8000 hours.

For the control group at $70^{\circ} \mathrm{F}$ in Figure 1, the resistance measurements remained within $\pm 0.8 \%$ over the 14 -month test period with random variation in measured values, up and down.

In Figure 2, the measured values have a similar random up and down movement within $\pm 1 \%$ of the starting value; however, it should be noted that there is a positive slope in the readings starting at about August 1992 and continuing through July 1993. However, this increasing circuit resistance (about $2 \%$ over 8000-hour period in saturated d-Limonene atmosphere) is not caused by the exposure to the saturated $d$-Limonene atmosphere but by the exposure to the $+160^{\circ} \mathrm{F}$ for 8000 hours, because this positive slope is seen also in the two other groups. The samples cleaned with TCE/IPA show a similar positive slope over the same time period, as shown in Figure 3. Units cleaned with d-Limonene/IPA show a similar positive slope but to a lesser degree, because of the shorter exposure to $+160^{\circ} \mathrm{F}$ (Figure 4).

Figure 5 shows leakage current data for a 28-channel high voltage transient suppresser assembly in the control group. The mean and \pm 3 sigma leakage current readings are determined for 14 identical filtered circuits. As expected for a control group unit, the leakage current readings remained constant within $\pm 9 \%$ over the 14 -month test period.
Figure 6 shows leakage current data for identical circuits, but from a different 28-channel high voltage transient suppresser assembly, in saturated d-Limonene atmosphere at $+160^{\circ} \mathrm{F}$, remaining constant within $\pm 10 \%$ throughout the 8000 -hour test. Again, there were no detectable aging effects.

Leakage current stability factors on the order of $\pm 10 \%$, as shown in previous paragraphs, are quite respectable considering that the measured currents are small, on the order of about $8 \times 10^{-9} \mathrm{~A}$, and that the measurements are made in an automated tester with 8-footlong unshielded cables between the unit under test and the tester. In addition, there are the switching relays and wiring inside the tester that can add to the noise in these measurements.

Figure 7 shows the average leakage current for 14 filtered lines at $+160^{\circ} \mathrm{F}$ for 3800 hours. This assembly has been cleaned with d-Limonene/IPA during all the assembly operations. The data in Figure 7 is typical of the leakage current measurements for the d-Limonene-cleaned units where the current starts high, $25 \times 10^{-9} \mathrm{~A}$ in July 1993 , and then drops to $8 \times 10^{-9} \mathrm{~A}$ by December 1993 and then remains at $8 \times 10^{-9} \mathrm{~A}$ through the 3800 -hour exposure to $+160^{\circ} \mathrm{F}$.

The initial reduction of the leakage current at room temperature from $25 \times 10^{-9} \mathrm{~A}$ to $8 \times 10^{-9} \mathrm{~A}$ is probably caused by the outgassing of the $d$-Limonene residue. I have never seen changes in leakage current like these in leakage current data from 1800 identical assemblies but cleaned with TCE/IPA. The only thing unique about these assemblies is that they were cleaned with d-Limonene/IPA. At the same time, I have experimented with test boards which I saturated with d-Limonene, but for which in spite of the $d$-Limonene, I was still measuring 
leakage currents on the order of $10^{-10}$ to $10^{-11} \mathrm{~A}$, two orders of magnitude less.

I do not have an explanation for the leakage current reduction shown in Figure 7.

However, it is important to note that the leakage current did stabilize at $8 \times 10^{-9} \mathrm{~A}$, typical to these circuits as shown in Figure 5 and Figure 6 and that it remained unaffected by the 3800 -hour exposure to $+160^{\circ} \mathrm{F}$,

Figure 7.

\section{Accomplishments}

After an 8000 -hour aging study at $+160^{\circ} \mathrm{F}$, there was no observable performance degradation in any of the four groups.

D-Limonene was shown to be an effective cleaner of the primary intentional contaminants (Kester 197 solder flux and RAM 225 mold release) and, therefore, a good replacement for TCE. ${ }^{1}$ The results of this study further support the use of d-Limonene as a replacement solvent for TCE by showing that 8000 hours at $160^{\circ} \mathrm{F}$ has not produced any performance degradation, even in the saturated d-Limonene atmosphere. 


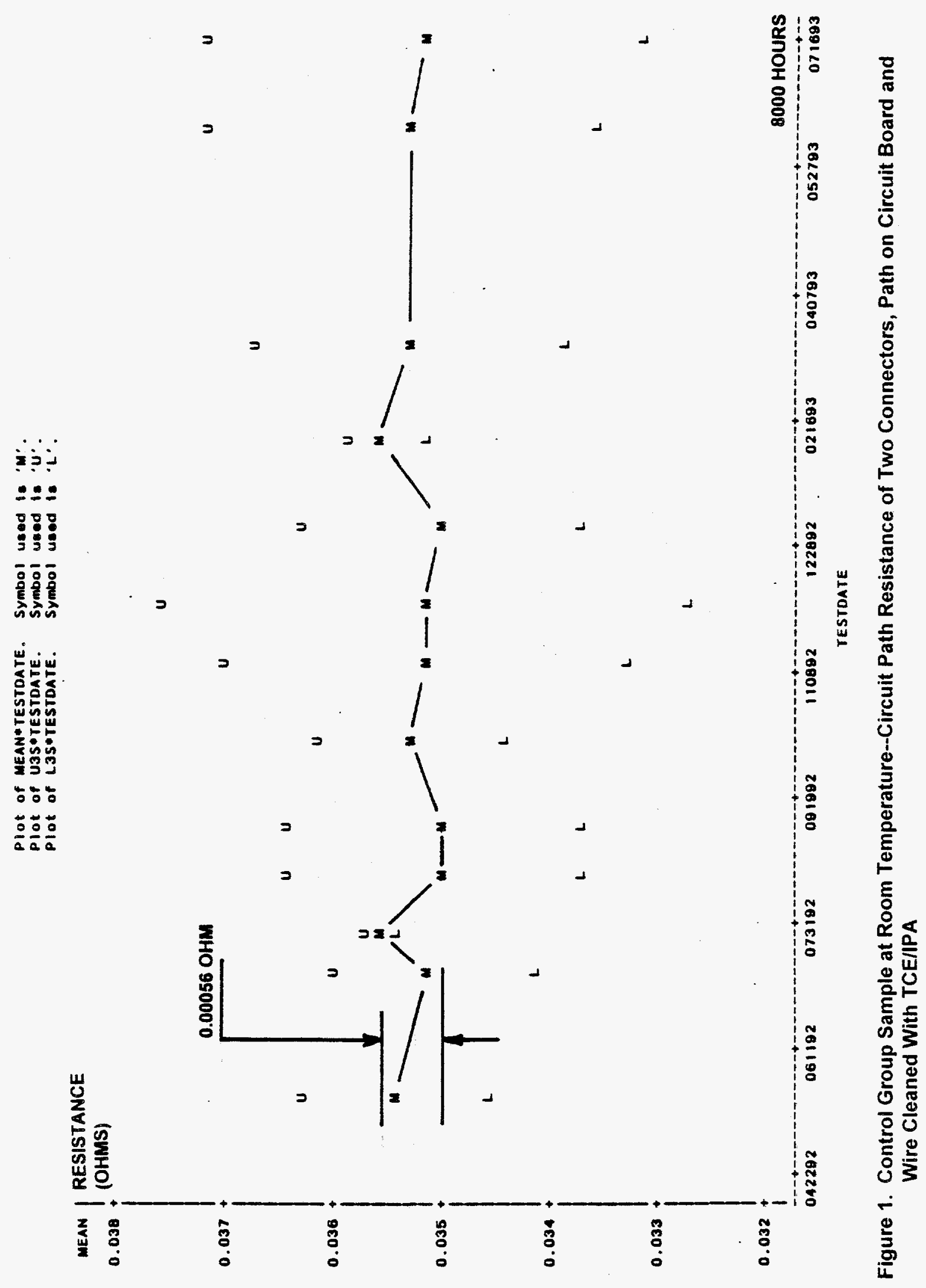


Plot of MEAN*TESTPATE. Symbol used is 'M'.

Plot of USS*TESTDATE. Symbol used is 'U:"

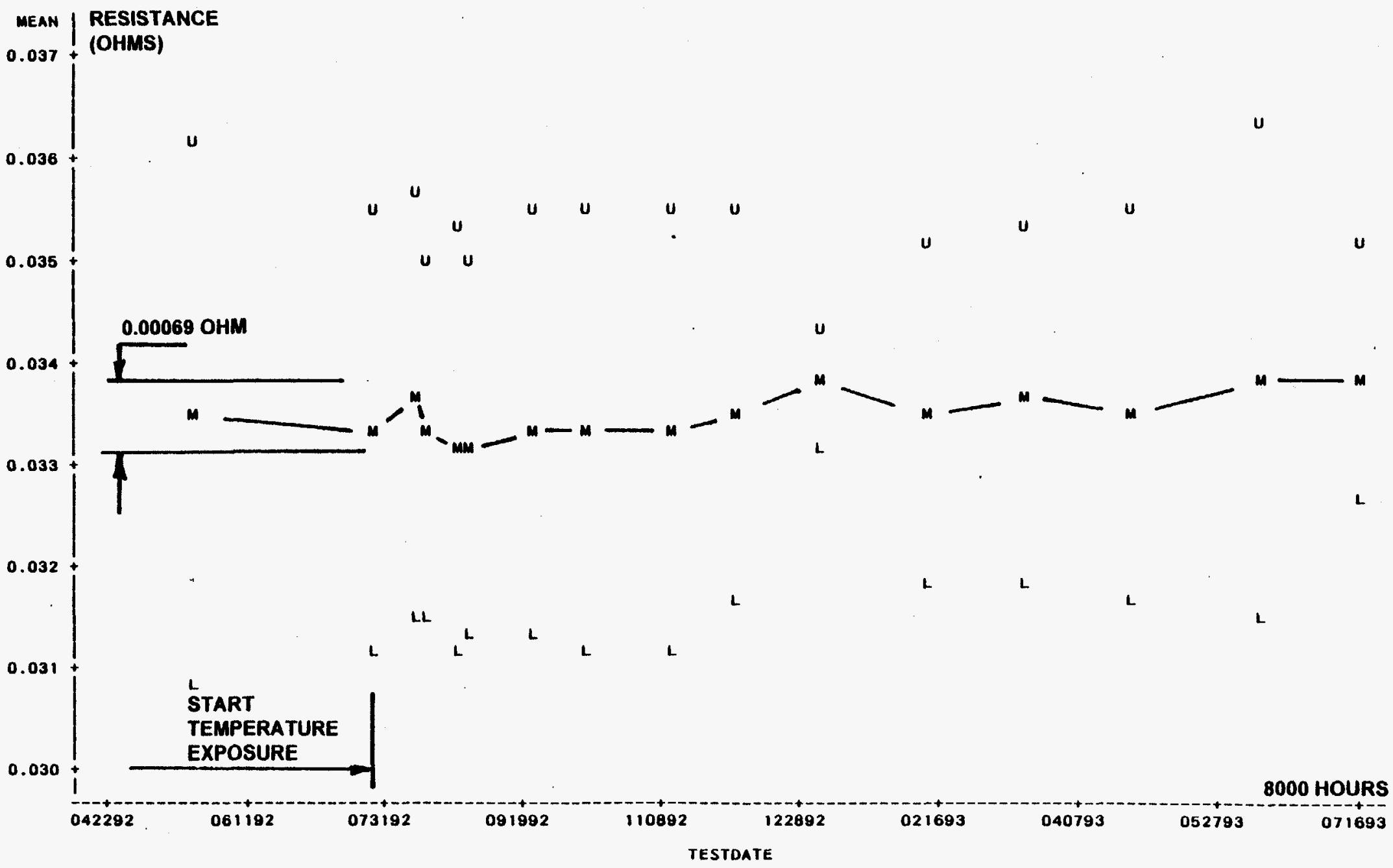

Figure 2. Circuit Path Resistance of Two Connectors, Circuit Board, and Wire-- 8000 Hours at $+160^{\circ}$ F, Saturated D-Limonene Atmosphere, Cleaned With TCEIIPA 


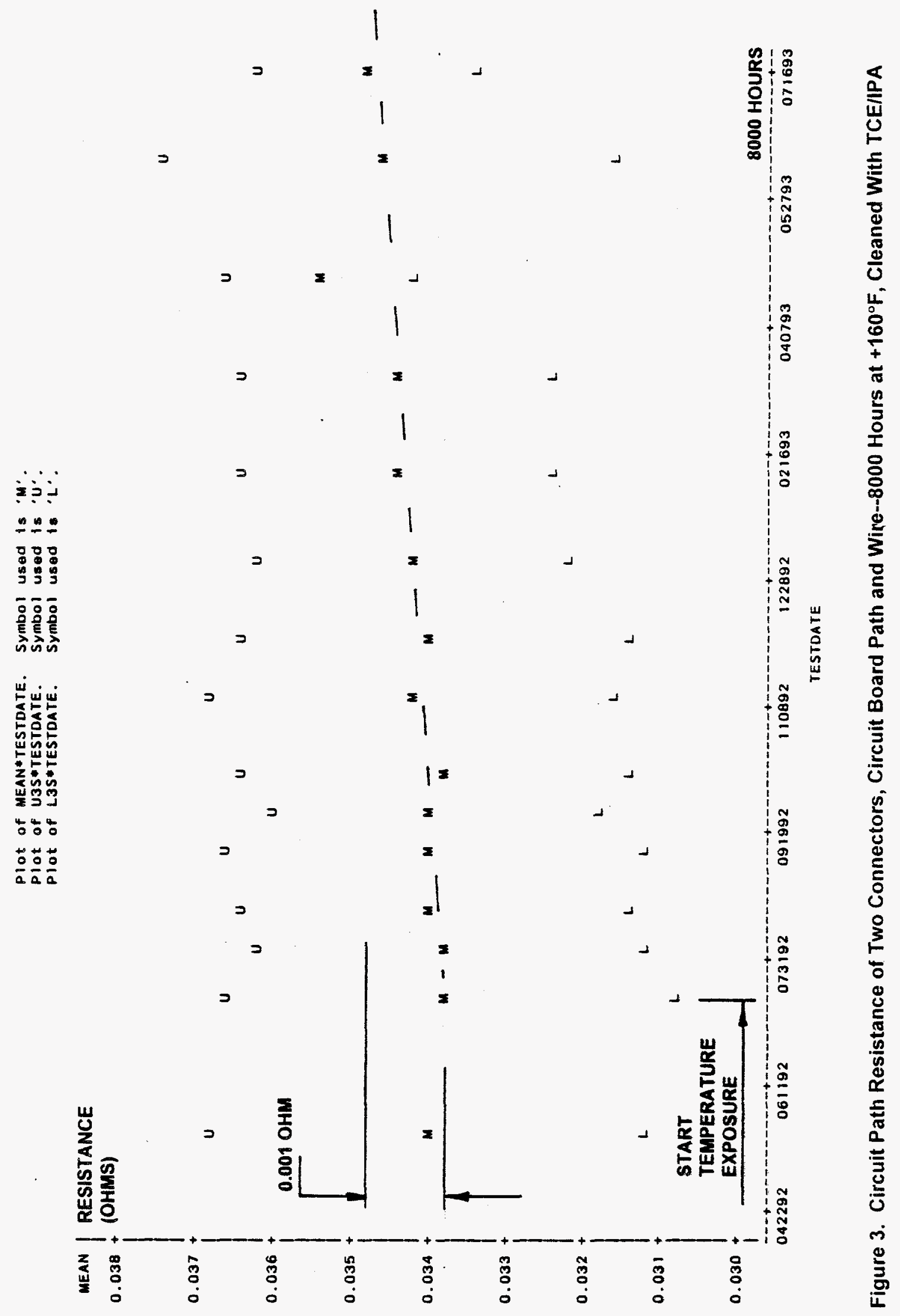


Plot of MEAN"TESTDATE. Symbol used is ' $M$ '.

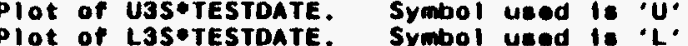

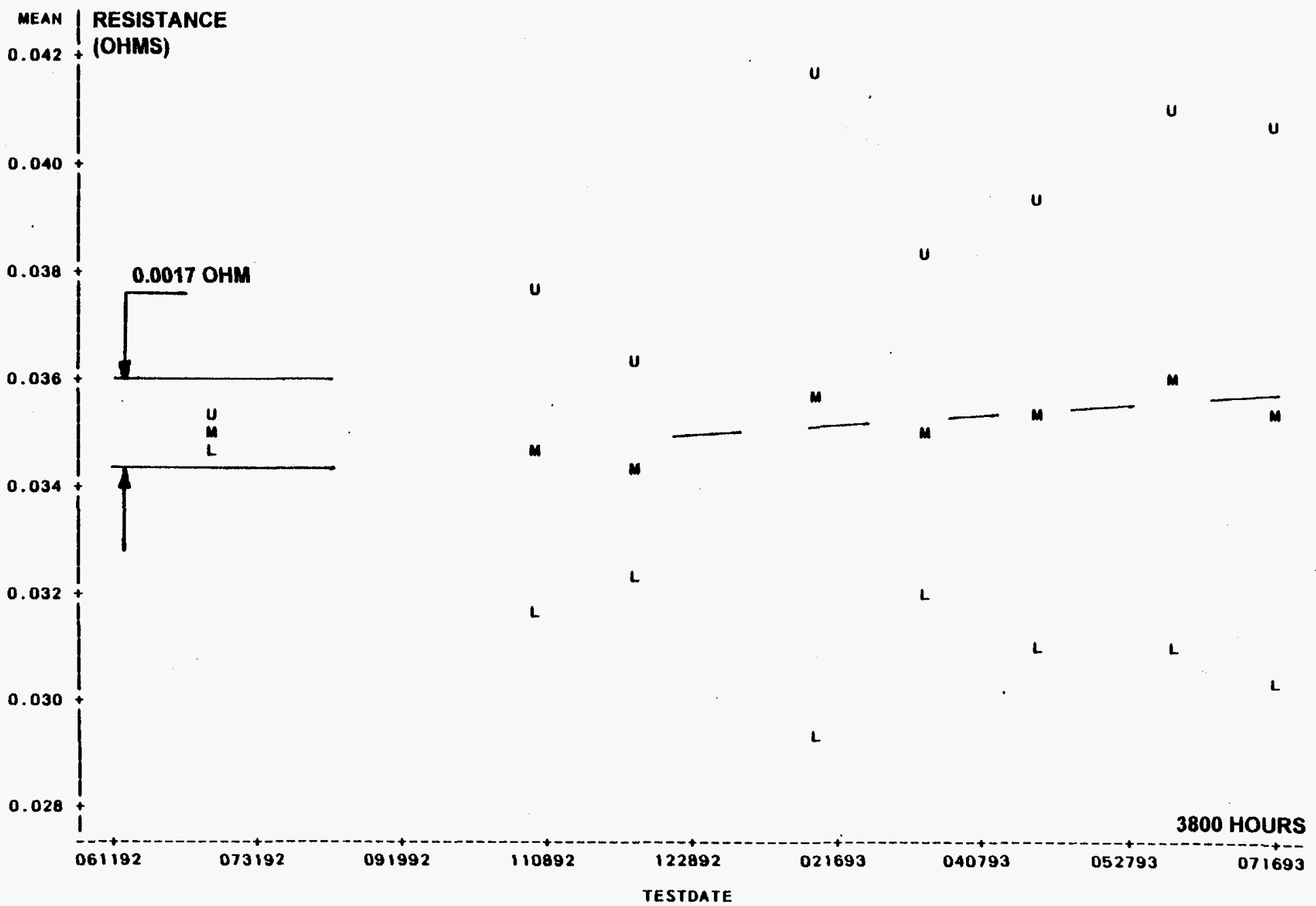

Figure 4. Circuit Path Resistance of Two Connectors, Circuit Board Path and Wire--3800 Hours at $+160^{\circ} \mathrm{F}$, Cleaned With D-Limonene/IPA 


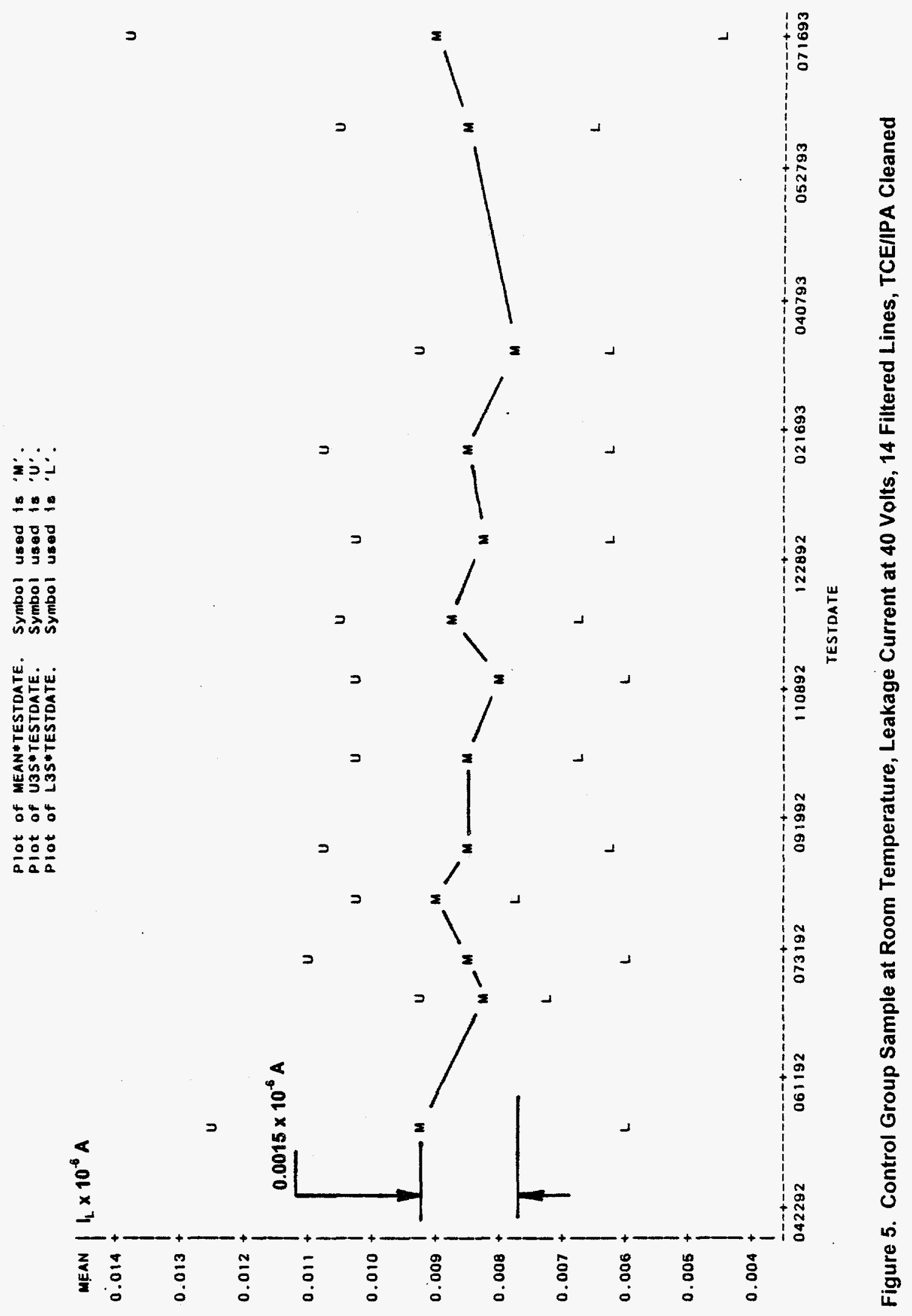


Plot of MEAN"TESTDATE. Symbol used to 'W'.

Plot of U3SoTESTOATE. Symbol used 10 'u

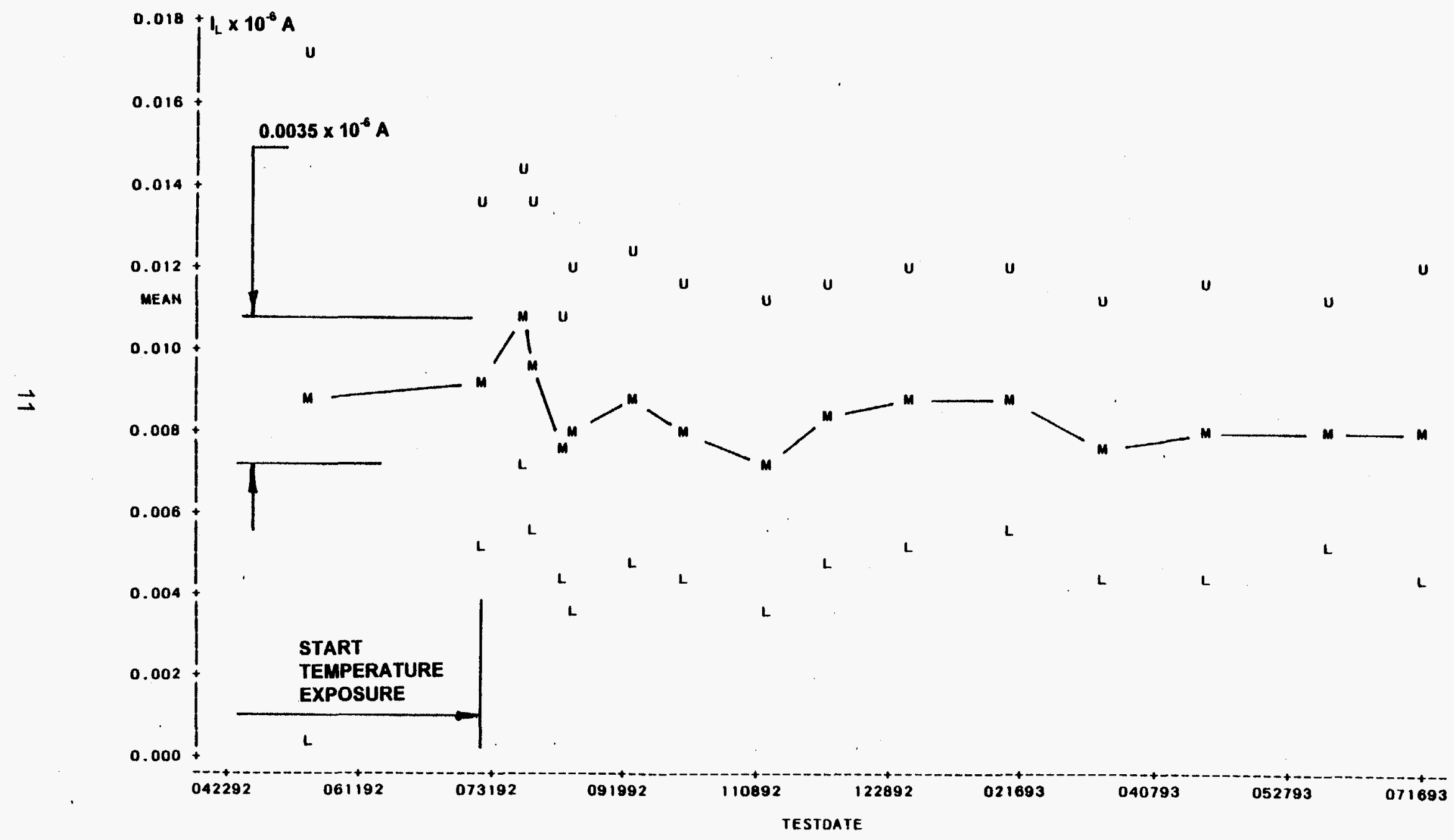

Figure 6. Leakage Current for 14 Filtered Lines (Ave) at 40 Volts--8000 Hours at $+160^{\circ} \mathrm{F}$, Saturated D-Limonene Atmosphere, TCE/IPA Cleaned 
Plot of MEAN*TESTDATE. Symbol usad is 'M'.

Plot of MEAN

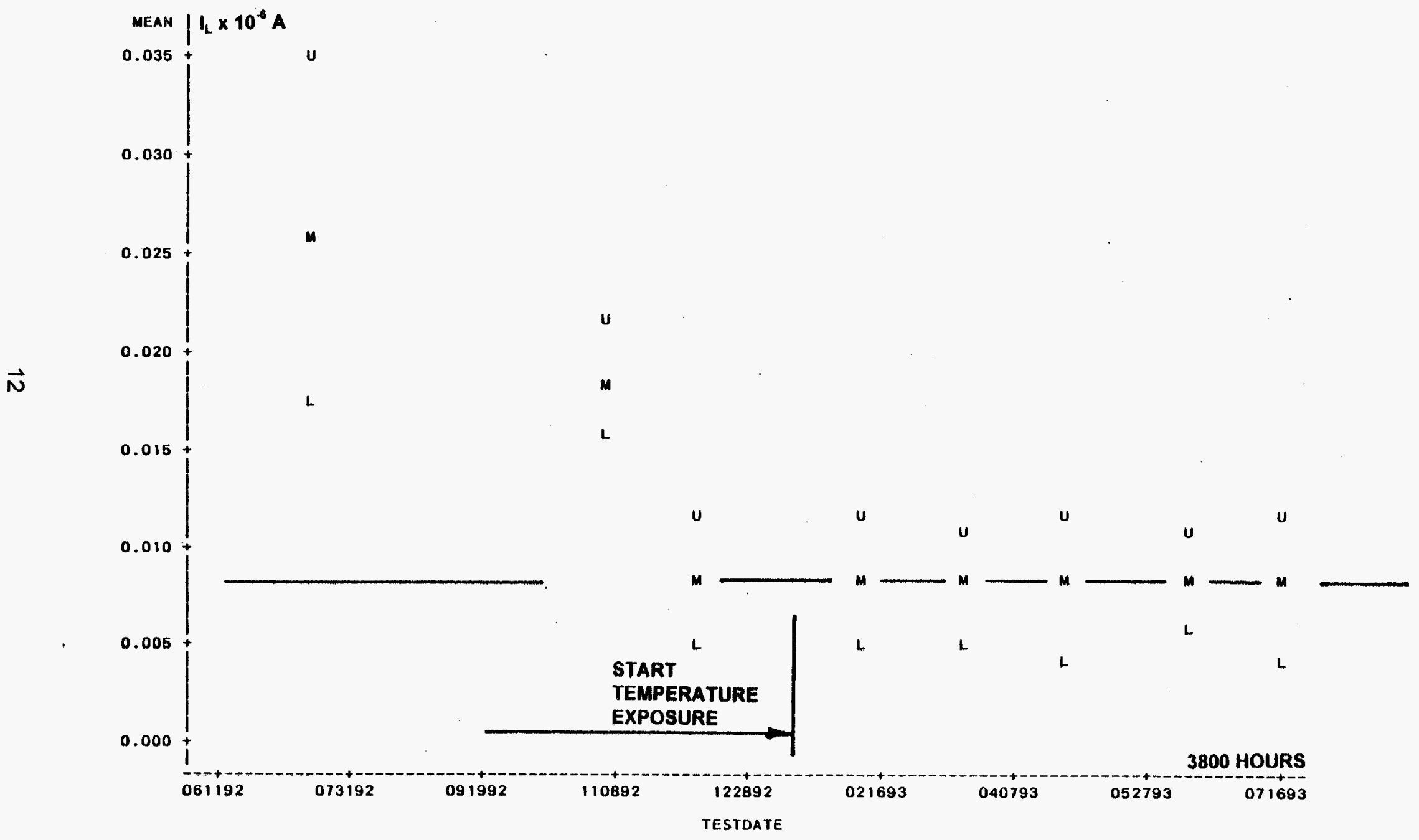

Figure 7. D-Limonene/IPA Cleaned Assemblies- -3800 Hours at $+160^{\circ} \mathrm{F}$ 


\section{Reference}

${ }^{1}$ M. G. Benkovich, "Solvent Substation for Electronic Products." International Journal of Environmentally Conscious Manufacturing, Vol. 1, No. 1, 1992. 